\title{
Manajemen Anestesi pada Pasien Seksio Sesarea Primigravida dengan Glioblastoma Multiforme
}

\author{
Ratih Kumala Fajar Apsari ,Bambang Suryono, Shinta \\ Departemen Anestesiologi dan Terapi Intensif Fakultas Kedokteran, Kesehatan Masyarakat dan Keperawatan \\ Universitas Gadjah Mada - RSUP Dr. Sardjito Yogyakarta
}

\begin{abstract}
Abstrak
Tumor otak pada kehamilan jarang terjadi, Glioblastoma multiforme adalah tumor otak primer yang paling agresif dan biasanya membawa prognosis yang buruk. Tumor otak pada kehamilan berkorelasi dengan terjadinya peningkatan mortalitas maternal, kelahiran premature dan intra uterine growth restriction (IUGR). Adanya tumor otak pada kehamilan akan mempengaruhi penentuan waktu persalinan, jenis dan tehnik anestesi yang akan digunakan. Kasus: Dilaporkan pasien dengan G1P0A0 Hamil 33 minggu, mengeluh sakit kepala hilang timbul sejak 6 bulan yang lalu. Sakit kepala berdenyut terutama sebelah kanan, tidak disertai mual, muntah, pandangan kabur dan kejang. Sakit kepala berkurang dengan obat paracetamol. Awal Mei 2017 pasien merasakan sakit kepala hebat disertai muntah proyektil, dilakukan pemeriksaan MRI kepala, curiga glioblastoma multiforme regio temporoparietal dextra. Diagnosa ditegakkan berdasarkan anamnesa, pemeriksan fisik dan pemeriksaan penunjang. Pasien telah dilakukan SC dengan tehnik regional anestesi epidural obat Levobupivacain $0.5 \%$ isobaric $11 \mathrm{ml}$, janin cukup viable dilahirkan dan mencegah peningkatan tekanan intracranial lebih lanjut. Pasien pulang ke rumah setelah perawatan 5 hari dalam kondisi baik. Pembahasan: Pada wanita hamil dengan tumor otak yang akan dilakukan SC, selama tidak ada kontraindikasi neuroaxial anestesi dapat dilakukan. Tehnik ini pun dilakukan dengan menjaga hemodinamik tetap stabil, mencegah peningkatan tekanan intracranial, seperti saat dilakukan dengan general anestesi. Simpulan: Selama tidak didapati kontraindikasi untuk anestesi neuroaxial, wanita hamil dengan SOL yang tidak mempunyai efek massa, hidrosefalus, atau klinis kearah peningkatan TIK, dapat dilakukan tindakan dengan neuroaxial anestesi.
\end{abstract}

Kata kunci: epidural; glioblastoma multiforme; primigravida; sectio caesarea

\section{Anesthesia Management for Cesarean Section in Patient with Glioblastoma Multiforme}

\begin{abstract}
A brain tumor in pregnancy is rare. Glioblastoma mutltiforme is the most aggressive tumor primary brain and usually have poor prognosis. A brain tumor in pregnancy are associated with increased mortalitas maternal, prematurity and intra uterine growth restriction. The presence of a brain tumor in pregnancy may affect the decision for timing of delivery, type and technique an anesthesia to be used. Case: Patients with G1P0A0 pregnant 33 weeks, complaining of recurrent headaches since 6 months ago. Headache pulsate especially on the right side, without nausea, vomiting, blurred vision or seizures. Headache is relieved with paracetamol. Patients felt a severe headache accompanied by projectile vomiting on May 2017. And performed head examination MRI, suspected glioblastoma multiforme temporoparietal dextra region based on anamnesis, physical examination and brain MRI. Patient has been performed caesarea section with regional anesthesia technique with epidural drug Levobupivacain $0.5 \%$ isobaric $11 \mathrm{ml}$. Patient returns home after 5 days in good condition. Discussion: A pregnant women with a brain tumor to be performed caesarea section procedure, neuroaxial anesthesia can be successfully applied as long as the patients do not have any contraindications. This technique is keeping the hemodynamics stable, preventing an increase in intracranial pressure as when performed with general anesthesia. Conclusion: As long as there is no contraindications are found for neuroaxial anesthesia, pregnant woment with space occupying lesion without mass effect, hydrocephalus or clinical evidence of increasing ICP can be treated with neuroaxial anesthesia.
\end{abstract}

Key words: epidural; caesarea section; glioblastoma multiforme; primigravida 


\section{Pendahuluan}

Tumor otak pada kehamilan jarang terjadi, insidensi kejadiannnya 15 per 100.000 dengan outcome yang bervariasi. Penyebab terjadinya tumor otak sangat kompleks dan belum diketahui. Sekitar $75 \%$ dari tumor intrakranial dialami pada wanita dengan usia produktif dan saat kehamilan. Pembesaran tumor selama kehamilan berkaitan dengan retensi cairan, akumulasi dari perubahan hormon, pembengkakan pembuluh darah, dan adanya reseptor hormon pertumbuhan yang menyebabkan progresivitas gejala neurologic selama kehamilan dan mengalami remisi setelah post partum. ${ }^{1}$

Glioblastoma multiforme (GBM) adalah tumor otak primer yang paling agresif dan biasanya membawa prognosis yang buruk. Penyakit rekuren juga memiliki hasil yang lebih buruk, dan kehamilan membuat situasi lebih menantang. Glioblastoma multiforme pada kehamilan dapat hadir dengan spektrum gejala dan tanda yang luas mulai dari yang ringan sampai yang berat. Gejala dapat berupa gejala umum, seperti sakit kepala, mual dan muntah, sinkop, dan gangguan kejang, atau gejala fokal yang umum terjadi meliputi gangguan visual, bahasa, motorik, dan sensorik 1 Tujuan pengobatan adalah untuk meminimalkan mortalitas dan morbiditas baik ibu dan janin dengan memperpanjang masa kehamilan sambil mengurangikomplikasidaritumorotak.Perubahan fisiologi pada kehamilan dapat meningkatkan laju pertumbuhan tumor dan meningkatkan tekanan intrakranial (TIK). Sebaliknya tumor otak pada kehamilan diketahui mempunyai korelasi dengan terjadinya peningkatan mortalitas maternal, kelahiran premature dan intra uterine growth restriction (IUGR). Adanya tumor otak pada kehamilan akan mempengaruhi penentuan waktu persalinan, jenis dan tehnik anestesi yang akan digunakan. Pada kasus ini pertimbangan anestesi pada Sectio Caesarean (SC) adalah adanya 2 insan yang harus diperhatikan yaitu keselamatan ibu dan janin, adanya perubahan fisiologi serta perubahan anatomi ibu yang menyebabkan perubahan dalam tehnik dan obat anestesi yang diberikan dan adanya risiko regurgitasi, aspirasi dan supine hypotension syndrome.
Pertimbangan lain adalah ibu masuk RS pada saat akan melahirkan sehingga persiapan prabedah minimal termasuk puasa prabedah. Puasa untuk SC elektif adalah 6-8 jam dari makanan padat. Dengan demikian prinsip obstetri anestesi adalah menjaga outcome yang baik bagi ibu dan janin, pengaturan aliran darah uteroplasental, obat tidak menembus barrier plasenta, dan target APGAR score yang baik.

Tehnik neuroanestesi harus dirancang untuk menghindari hipoksia janin, hiperkarbia, hipotensi, serta perubahan fisiologi fetomaternal. Prinsip neuroanestesi adalah mencegah terjadinya cedera sekunder. Cedera sekunder bisa terjadi pada cedera otak traumatik, tumor otak, penyakit serebrovaskuler (stroke hemoragik, stroke iskemik). Tehnik anestesi dengan ABCDE neuroanestesi, yang sama dengan neuroresusitasi, neuroproteksi, pengelolaan neuro ICU. Prinsip neuroprotektif pada pasien hamil dengan tumor otak adalah memperhatikan keseimbangan antara neuroprotektif yang optimal buat ibu dan mengurangi efek yang merugikan pada fetus. ${ }^{2}$ Laporan kasus ini bertujuan untuk membahas lebih lanjut penatalaksanaan anestesi pada SC dengan tumor otak, glioblastoma multiforme.

\section{Anatomi dan Fisiologi Intrakranial}

Memahami hubungan antara tekanan intrakranial (TIK) dan herniasi otak, adalah hal yang penting untuk memahami compliance intrakranial. Compliance merupakan hubungan antara TIK dan volume komponen primer intrakranial; otak, cerebrospinal fluid (CSF), dan darah; dengan struktur rigid kranium. Ilustrasi konstribusi volume relatif dari 3 komponen intrakranial pada kondisi normal (Gambar 1).

Jaringan otak sekitar $1400 \mathrm{ml}$ terdiri dari paling banyak cairan intra dan ekstraseluler. Volume jaringan otak dapat meningkat melalui pertumbuhan abnormal sel tumor jinak atau maligna atau peningkatan cairan intra atau ekstraseluler. Tumor otak maligna, salah satu bentuk space occupying lesion (SOL), yang sering berhubungan dengan edema lokal, jaringan nekrotik, dan perdarahan, dimana dapat meningkatkan volume otak. ${ }^{3-4}$ 


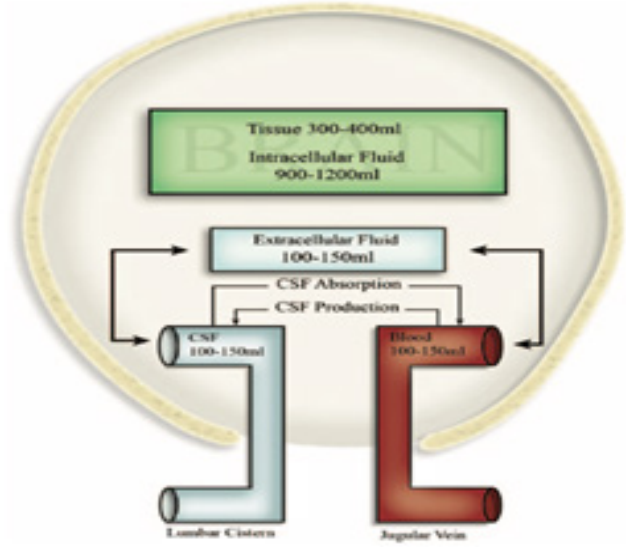

Gambar 1. Ilustrasi 3 Komponen Intrakranial ${ }^{3}$

Volume CSF intrakranial sekitar $150 \mathrm{ml}$ dan berada di dalam ventrikel, sebuah sistem penghubung antara ruang/kavitas intrakranial dengan ruang spinal subarahnoid dan sisterna lumbar. CSF dibentuk terutama di pleksus khoroideus, melalui difusi transependimal. CSF dibentuk dan direabsorpsi dengan kecepatan 18-25 ml/jam atau 500-600 ml/hari. CSF mengalir dari ventrikel lateral melalui foramina intraventrikuler (Monro), ke dalam ventrikel III, melalui aquaductus sylvii, ke ventrikel IV, melalui foramen magendie di median dan foramen luschka di lateral kedalam sisterna magna. Selanjutnya CSF memasuki rongga subarakhnoid, bersirkulasi mengelilingi otak dan medula spinalis sebelum diabsorpsi ke dalam sistem vena otak oleh vili yang ada di selaput arakhnoid hemisfer otak. Tekanan CSF normal antara $13-20 \mathrm{~cm} \mathrm{H}_{2} \mathrm{O}$ dengan manometer. ${ }^{4-6}$

Darah dalam pembuluh darah intrakranial mempunyai fungsi vital untuk pertukaran oksigen, karbondioksida, glukosa, dan asam amino dengan jaringan otak. Volume darah otak normal sekitar $150 \mathrm{ml}$, dipengaruhi oleh beberapa faktor, termasuk vasokonstriksi dan vasodilatasi terhadap respon lingkungan jaringan lokal atau tekanan parsial karbondioksida. Sawar darah otak mempunyai regulasi untuk aliran nutrisi, ion, dan cairan ke otak, sebagai barrier. Meskipun hal ini kompleks, namun banyaknya lapisan membran didesain untuk mendukung aktivitas elektrik neuron dan metabolisme yang optimal. Pada kondisi adanya tumor maligna atau kondisi eklampsia, akan mengganggu sawar darah otak menjadi edema vasogenik, dimana akan meningkatkan cairan ekstraseluler, dan volume jaringan otak, di dalam kranium. Kelainan pada dinding arteri atau vena dapat menghasilkan segmen displastik atau aneurisma, malformasi arterivena atau fistula yang mudah berdarah, diseksi, atau tersumbat. Ketika terjadi ruptur pembuluh darah, akan terjadi perdarahan intrakranial seperti subdural, intraserebral, atau subarakhnoid hemoragik. Hal ini dapat meningkatkan TIK dengan menggangu aliran dari CSF, membentuk efek massa pada sistem ventrikel atau trombosis dalam ventrikel. ${ }^{4}$ Tidak adanya compliance pada tulang kranium, jumlah total volume intrakranial adalah tetap. Hal ini dinyatakan bila ada peningkatan pada salah satu komponen intrakranial, maka akan terjadi kompensasi penurunan dari volume komponen intrakranial lainnya. Hal ini dikenal sebagai Monro Kellie doctrine. Compliance intrakranial merupakan perubahan volume untuk setiap perubahan tekanan. ${ }^{4}$

\section{Neoplasma Otak}

Neoplasma otak pada wanita hamil mempunyai frekuensi relatif sama dengan wanita tidak hamil, meskipun pengaruh fisiologi yang terjadi selama kehamilan dapat mempengaruhi implikasi dari gejala klinis dan manajemennya. Klasifikasi

Tabel 1. Klasifikasi Neoplasma Otak pada Wanita

\begin{tabular}{|c|c|c|}
\hline TABLE 49-4 & \multicolumn{2}{|c|}{$\begin{array}{l}\text { Classification of Brain Tumors } \\
\text { in Women }\end{array}$} \\
\hline Histologic Ty & & $\begin{array}{l}\text { Percentage of all } \\
\text { Diagnosed Tumors }\end{array}$ \\
\hline \multicolumn{3}{|l|}{ Benign } \\
\hline Meningioma & & 35 \\
\hline Schwannom & & 7 \\
\hline Pituitary neo & lasms & 7 \\
\hline \multicolumn{3}{|l|}{ Malignant } \\
\hline \multicolumn{3}{|l|}{ Gliomas: } \\
\hline Low-grade & astrocytoma & 3 \\
\hline $\begin{array}{l}\text { Glioblastor } \\
\text { (plus hig } \\
\text { astrocytc }\end{array}$ & $\begin{array}{l}\text { a multiforme } \\
\text {-grade } \\
\text { ma) }\end{array}$ & 23 \\
\hline Other astrc & cytoma & 8 \\
\hline Other & & 5 \\
\hline Lymphoma & & 2 \\
\hline Medulloblast & ma & 2 \\
\hline Other brain $r$ & eoplasms & 8 \\
\hline
\end{tabular}


neoplasma otak pada wanita (Tabel 1). ${ }^{7}$ Glioma merupakan neoplasma intrakranial paling sering terjadi sekitar 39\% dari seluruh tumor primer intrakranial. Glioma diklasifikasikan berdasarkan asal embriologis. Pada orang dewasa, sel neuroglia susunan saraf pusat berfungsi untuk perbaikan, penyokong dan pelindung sel-sel saraf yang lunak. Glioma terdiri dari jaringan penyambung dan sel-sel penyokong. Neuroglia mempunyai kemampuan untuk terus membelah selama hidup. Sel-sel glia berkumpul membentuk parut sikatriks padat di bagian otak dimana neuron menghilang oleh karena cedera atau penyakit.

Terdapat tiga jenis sel glia: mikroglia, oligodendroglia dan astrosit. Mikroglia secara embriologis berasal dari lapisan mesodermal dan oleh karena itu pada umumnya tidak diklasifikasikan sebagai sel glia sejati. Mikroglia masuk ke dalam susunan saraf melalui sistem pembuluh darah dan berfungsi sebagai fagosit, membersihkan debris, dan berperang melawan infeksi. Oligodendroglia dan astrosit merupakan neuroglia sejati dan seperti neuron berasal dari lapisan embrional ektodermal. Oligodendroglia berperan dalam pembentukan myelin. Fungsi astrosit menyediakan nutrisi esensial yang diperlukan oleh neuron dan membantu neuron mempertahankan potensial bioelektris yang sesuai untuk konduksi impuls dan transmisi sinaptik.

Astrositoma menginfiltrasi otak dan sering berkaitan dengan kista dalam berbagai ukuran. Walau menginfiltrasi jaringan otak, efeknya pada fungsi otak hanya sedikit sekali pada permulaan penyakit. Pada umumnya, astrositoma tidak ganas, walaupun dapat mengalami perubahan keganasan menjadi glioblastoma, suatu astrositoma yang sangat ganas. Tumor-tumor ini pada umumnya tumbuh lambat. Oleh karena itu penderita sering tidak datang berobat walaupun tumor sudah berjalan bertahun-tahun, sampai timbul gejala, misalnya serangan epilepsi atau nyeri kepala. Pada pembedahan, eksisi lengkap pada umumnya tidak mungkin karena sifat invasif tumor. Glioblastoma multiforme (GBM) adalah glioma yang paling ganas. Tumor ini mempunyai kecepatan pertumbuhan yang sangat tinggi, dan eksisi bedah yang lengkap tidak mungkin dilakukan. Harapan hidup pada umumnya kirakira 12 bulan. Tumor ini dapat terjadi dimana saja tetapi paling sering pada hemisfer serebri dan sering menyebar ke sisi yang berlawanan melalui korpus kalosum. Lokasi yang paling sering untuk GBM adalah hemisfer serebri; dengan 95\% dari tumor ini muncul di daerah supratentorial, sementara hanya beberapa persen tumor terjadi di serebelum, batang otak dan medula spinalis. Oligodendroglioma mirip dengan astrositoma namun terdiri dari sel-sel oligodendroglia. Tumor relatif avaskuler dan cenderung mengalami kalsifikasi. Ependimoma adalah tumor ganas yang berasal dari bagian dalam dinding ventrikel. Pada anak-anak tempat yang paling sering adalah ventrikel IV. Tumor ini menyerang jaringan sekitarnya dan menyumbat ventrikel. Kematian biasanya terjadi dalam 3 tahun atau kurang. ${ }^{7}$

\section{Manifestasi Klinis}

Trias klasik tumor otak adalah nyeri kepala, muntah dan papilledema. Namun gejala sangat bervariasi bergantung pada tempat lesi dan kecepatan pertumbuhannya.

\section{Nyeri Kepala}

Barangkali nyeri kepala merupakan gejala umum yang paling sering dijumpai pada penderita tumor otak. Nyeri dapat digambarkan bersifat dalam, terus-menerus, tumpul dan kadang-kadang hebat sekali. Nyeri ini paling hebat saat pagi hari dan menjadi lebih hebat oleh aktivitas yang biasanya meningkatkan tekanan intracranial, seperti membungkuk, batuk, atau mengejan pada waktu buang air besar. Nyeri kepala yang dihubungkan dengan tumor otak disebabkan oleh traksi dan pergeseran struktur peka nyeri dalam rongga intrkranial. Struktur peka nyeri ini termasuk arteri, vena, sinus-sinus vena dan saraf otak.

\section{Mual dan Muntah}

Mual dan muntah terjadi sebagai akibat rangsangan pusat muntah pada medulla oblongata. Muntah paling sering terjadi pada anak-anak dan berhubungan dengan peningkatan tekanan intrakranial disertai pergeseran batang otak. Muntah dapat terjadi tanpa didahului mual dan dapat proyektil. 


\section{Papiledema}

Papiledema disebabkan oleh stasis vena yang menimbulkan pembengkakan papil saraf optikus. Bisa terlihat pada pemeriksaan funduskopi, tanda ini mengisyaratkan peningkatan tekanan intrakranial. Seringkali sulit untuk menggunakan tanda ini sebagai diagnosis tumor otak oleh karena pada beberapa individu fundus tidak memperlihatkan edema meskipun tekanan intrakranial meningkat. Tanda dan gejala lain dari tumor otak cenderung mempunyai nilai lokasi. ${ }^{7}$

\section{Kasus}

Pasien seorang wanita 25 tahun, gravid 1 paritas 0 abortus 0 hamil 33 minggu masuk rumah sakit direncanakan untuk terminasi kehamilan. Pasien adalah penderita glioblastoma multiforme regio temporoparietal dextra tegak sejak \pm 1 bulan yang lalu. Saat ini pasien tidak ada keluhan sakit kepala, mual, muntah, pandangan kabur dan kejang. Pasien saat ini tidak ada keluhan perut terasa kenceng-kenceng, flek pervaginam, dan keluar air ketuban. Pasien mengeluh sakit kepala hilang timbul sejak 6 bulan yang lalu. Sakit kepala berdenyut terutama sebelah kanan, tanpa disertai mual, muntah, pandangan kabur dan kejang. Sakit kepala berkurang dengan paracetamol. Awal Mei 2017 pasien merasakan sakit kepala hebat disertai muntah proyektil. Saat itu pasien dirawat di rumah sakit selama 2 hari

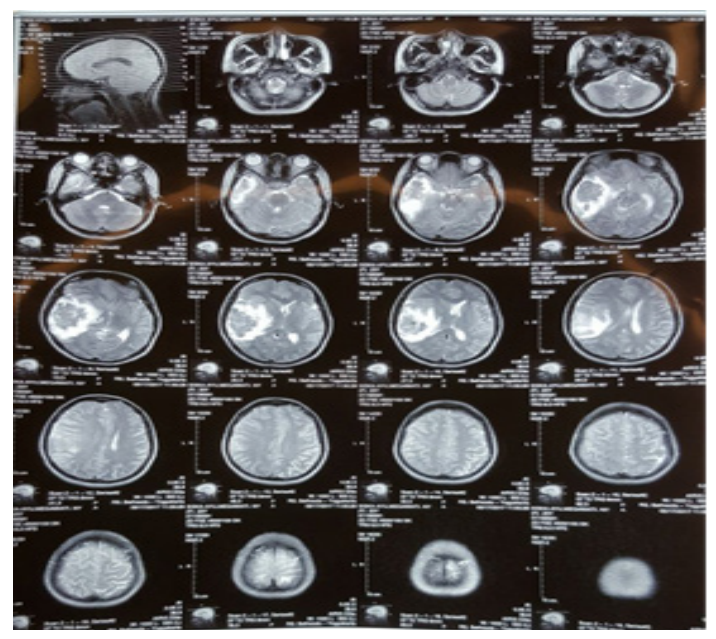

dan dilakukan pemeriksaan MRI kepala, dicurigai glioblastoma multiforme regio temporoparietal dextra. Kemudian pasien dirawat di rumah sakit untuk pematangan paru janin. Saat itu pasien mendapat terapi dexametason $1 \mathrm{x} 4 \mathrm{mg}$ per oral dan acetazolamid 2x125 mg per oral (1 seri).

Pada pemeriksaan fisik secara umum baik, dengan tanda vital tekanan darah 110/70 $\mathrm{mmHg}$ HR 80x/menit, laju nafas $20 \mathrm{kali} / \mathrm{menit}$, suhu $36.5^{\circ} \mathrm{C}, \mathrm{SpO}_{2} 99 \%$ room air. Tidak ditemukan tanda peningkatan tekanan intracranial, deficit neurologis dan papilla edema saat pemeriksaan.

Pada pemeriksaan laboratorium didapatkan hemoglobin $11.8 \mathrm{~g} / \mathrm{dL}$, hematokrit $35.6 \%$, angka trombosit $302 \times 103 / \mathrm{uL}$, leukosit $15.85 / \mathrm{mm} 3$, Albumin $3.82 \mathrm{~g} / \mathrm{dL}$, SGOT $15 \mathrm{U} / \mathrm{L}$, SGPT 9 U/L, PT 13.5/14.9 detik, APTT 30.5/28.6 detik, INR 0.98, GDS $137 \mathrm{mg} / \mathrm{dL}$, Ureum $5.1 \mathrm{mg} / \mathrm{dL}$, Kreatinin $0.53 \mathrm{mg} / \mathrm{dL}$, Natrium $135 \mathrm{mmol} / \mathrm{L}$, Kalium $3.89 \mathrm{mmol} / \mathrm{L}$, klorida $98 \mathrm{mmol} / \mathrm{L}$. Pada pemeriksaan elektrokardiografi didapati hasil sinus ritme dengan laju nadi $80 \mathrm{kali} /$ menit. Pada pemeriksaan ultrasonografi didapati hasil janin tunggal presentasi kepala. DJJ $(+)$ Plasenta di korpus posterior, air ketuban cukup. Pada pemeriksaan MRI brain didapatkan hasil massa di lobus temporoparietalis dextra dengan perifokal edema disekelilingnya yang mendesak struktur ventrikel lateralis dextra dan brainstem. Dari data yang didapat maka disimpulkan pasien

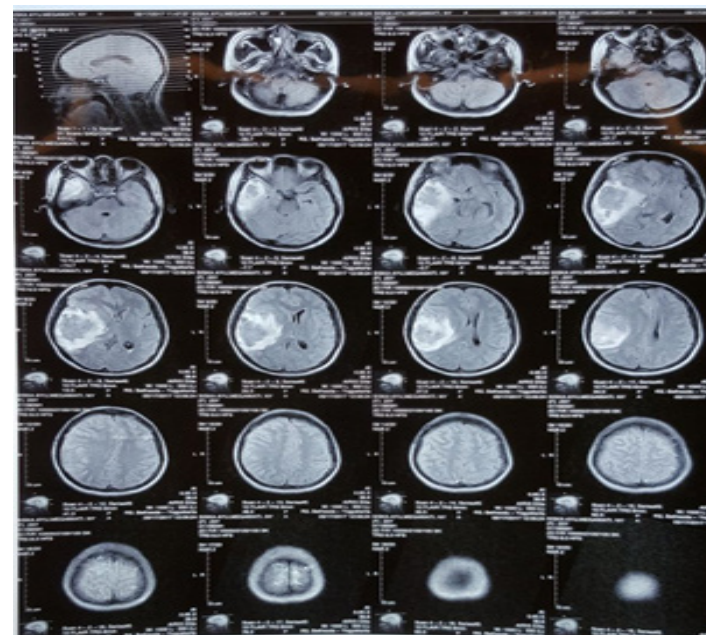

Gambar 2. Hasil MRI Brain:

Massa di Lobus Temporoparietalis Dextra dengan Perifokal Edema disekelilingnya yang Mendesak Struktur Ventrikel Ateralis Dextra dan Brainstem 
dengan status fisik ASA 2 dengan rencana pembiusan regional anestesi epidural anestesi. Persiapan yang dilakukan lengkapi informed consent anestesi, puasa 8 jam pre operasi, pasang infus dengan transfusi set abbocath no.18 G, sedia darah PRC 1 unit/bag Golongan darah $\mathrm{O}(+)$. Pasien diterima di ruang penerimaan pasien sudah terpasang IV line transfusi set abbocath no.18G dengan cairan RL. Diberikan cairan RL $500 \mathrm{ml}$ selama 30 menit sebelum masuk kamar operasi. Pasien masuk kamar operasi, dilakukan pemasangan monitor untuk tekanan darah, EKG, pulse oxymetri. Terbaca di monitor TD 124/83 $\mathrm{mmHg}, \mathrm{HR}$ 102x/menit, RR 20x/menit, $\mathrm{SpO}_{2}$ 98\%. Pemberian oksigen melalui nasal kanul 3 lpm. Tehnik anestesi dengan RA Epidural sitting position, puncture setinggi L3-L4 LOR $(+)$, jarum Tuohy no. $18 \mathrm{G}$, obat Levobupivacain $0.5 \%$ isobaric $11 \mathrm{ml}$. Pasien diposisikan supine. Pin prick tercapai setinggi Th VI. Operasi berlangsung selama 1 jam. Perdarahan $500 \mathrm{ml}$. Durante operasi tekanan darah sistolik $120-100 \mathrm{mmHg}$, tekanan diastolik 60-83 mmHg, HR 80-102x/menit, RR 18-20x/menit, $\mathrm{SpO}_{2}$ 98-100\%. Diberikan oksitosin 10 UI drip dalam RL $500 \mathrm{ml}$ post janin dilahirkan. Ondansetron $4 \mathrm{mg}$ iv, ketorolac $30 \mathrm{mg}$ iv. Pasca operasi pasien di observasi di recovery room, selanjutnya dirawat di bangsal.

\section{Pembahasan}

Tumor otak pada kehamilan telah diketahui berhubungan dengan meningkatkan resiko mortalitas pada ibu, kelahiran premature, pertumbuhan janin yang terlambat (intra uterine growth restriction/IUGR) dan meningkatnya kejadian persalinan seksio sesaria. Pertumbuhan janin yang terhambat disebabkan karena tumor otak mengambil nutrisi yang seharusnya untuk ibu dan janin, sehingga terjadi defisiensi nutrisi yang menyebabkan terhambatnya pertumbuhan janin tersebut. ${ }^{12}$ Kehamilan itu sendiri menghasilkan perubahan fisiologis yang signifikan yang membuat wanita lebih rentan terhadap stres, termasuk peningkatan tekanan intracerebral karena adanya tumor otak. Koeksistensi lesi ini selama kehamilan menciptakan dilema dan tantangan besar bagi tim multidisipliner yang harus menangani kasus-kasus ini, mempertimbangkan kebutuhan untuk perawatan bedah dan radioterapi untuk tumor ini. Waktu optimal untuk penghentian kehamilan ditentukan berdasarkan viabilitas janin, prognosis pasien, efek obat anestesi pada janin, ibu dan fisiologi otak. $^{12}$ Kehamilan merupakan faktor yang memberatkan pada tumor otak melalui aktivasi pertumbuhan tumor oleh stimulasi reseptor tumor karena hormon kehamilan, estrogen dan progesteron; melalui peningkatan edema epitumoral karena peningkatan volume sirkulasi darah dan penyumbatan pembuluh darah ibu; dan akhirnya, melalui toleransi kekebalan yang berbatasan dengan kehamilan.

Pada preoperatif didapatkan pasien mengeluh sakit kepala hilang timbul sejak 6 bulan yang lalu. Sakit kepala berdenyut terutama sebelah kanan, tanpa disertai mual, muntah, pandangan kabur dan kejang. Sakit kepala berkurang dengan paracetamol. Awal Mei 2017 pasien merasakan sakit kepala hebat disertai muntah proyektil. Saat itu pasien dirawat di RS Bethesda selama 2 hari dan dilakukan pemeriksaan MRI kepala, dicurigai glioblastoma multiforme regio temporoparietal dextra. Pasien adalah G1P0A0 hamil 33 minggu dan direncanakan untuk terminasi kehamilan. Saat ini pasien didiagnosa sebagai primigravida G1P0A0 hamil 33 minggu dengan Glioblastoma multiforme. Pertimbangan untuk dilakukan terminasi kehamilan, dikarenakan bayi dinilai cukup viable untuk dilahirkan dengan kondisi hemodinamik ibu masih baik, dengan tumor otak yang semakin membesar dan dapat meningkatkan tekanan intrakranial lebih lanjut. Diharapkan janin dilahirkan dalam kondisi baik. Sesuai patofisiologi pada kehamilan dimana terjadi peningkatan jumlah volume darah dan retensi cairan, maka akan membuat edema pada tumor dan pembesaran tumor. Pada tumor meningioma dan neuroma akustik, pertumbuhannya dipengaruhi oleh hormon reproduksi sehingga lebih mudah membesar pada saat kehamilan. ${ }^{9}$

Steroid umumnya digunakan pada pasien dengan glioma untuk mengurangi edema peritumoral. Dan pemberiannya dapat dipercepat pada pasien hamil prematur untuk mempercepat pematangan paru janin, mengurangi risiko perdarahan 


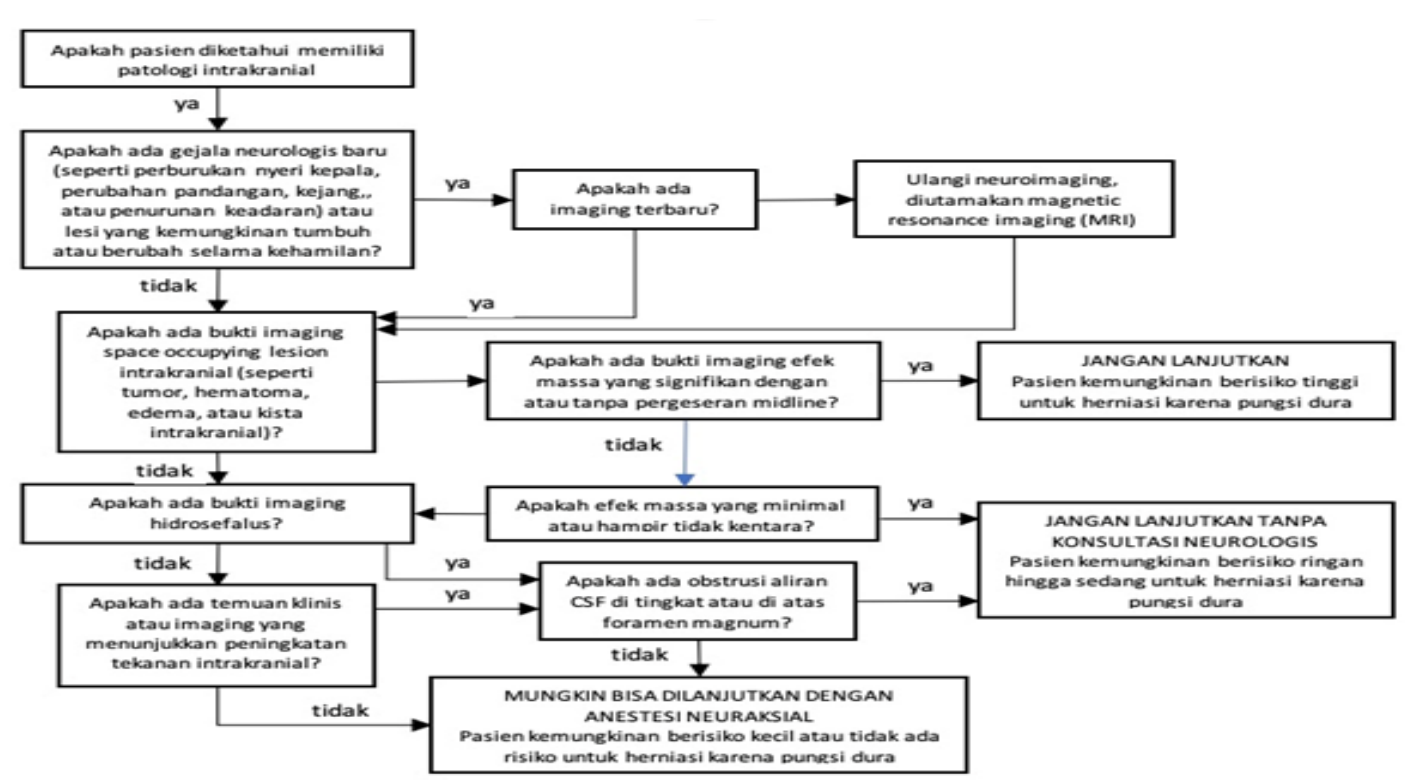

Gambar 7. Alur pengambilan keputusan yang merangkum elemen-elemen penting dalam penilaian risiko perburukan neurologis karena anestesi neuraksial pada pasien dengan space-occupying lesion intrakranial, CSF = cerebrospinal fluid

intraventrikular, dan penurunan mortalitas pada bayi prematur. Pilihan kortikosteroid adalah 2 dosis betametason $12 \mathrm{mg}$ intramuskular atau 4 dosis dexametasone $6 \mathrm{mg}$ intramuskular. Sementara dexamethasone umumnya digunakan untuk pasien bedah saraf, data observasi menunjukkan bahwa betametason mungkin lebih baik dalam mengurangi kematian neonatal. Karena usia kehamilan dan temuan pada MRI, maka diputuskan oleh teman sejawat obsgin dan perinatology untuk memulai terapi dengan deksametason sebagai kontrol edema serebral dan memungkinkan waktu untuk perkembangan pematangan paru janin. Pada pasien ini menggunakan deksametason $4 \mathrm{mg}$ selama 2 minggu untuk membantu pematangan paru janin.

Pada pasien ini direncanakan untuk dilakukan terminasi kehamilan dengan SC dan selanjutnya direncanakan untuk kraniotomi removal tumor 2 minggu post partum. Pasien menolak untuk dilakukan tindakan kraniotomi removal tumor. Ini merupakan tantangan memberikan anestesi pada pasien dengan tumor otak dengan kehamilan dengan mempertahankan perfusi uterus dan plasenta yang adekuat sambil menghindari peningkatan lebih lanjut pada TIK. Penentuan waktu persalinan pada pasien dengan tumor otak diutamakan berdasarkan viabilitas dari janin. Pada kehamilan yang janinnya belum dianggap viable, terapi radiasi atau stereotactic radiosurgery dapat dipertimbangkan untuk menurunkan ukuran masa tumor. Namun radioterapi dan kemoterapi dapat merugikan janin dalam kandungan bila dilakukan pada trimester pertama. Wanita hamil dengan tumor otak seringkali diasumsikan dengan peningkatan TIK dan beresiko untuk terjadi herniasi, sehingga seringkali dikontraindikasikan untuk dilakukan neuroaxial anestesi. Untuk dilakukan spinal atau epidural analgesia atau anestesi epidural secara aman pada pasien tersebut maka harus dipahami faktorfaktor yang berkonstribusi untuk mendukung adanya gejala klinis yang signifikan terhadap bergesernya jaringan otak, seperti peningkatan TIK, edema serebri, atau hidrosefalus. Dokter anestesi harus mempertimbangkan risiko dan keuntungan dari tindakan neuroaxial anestesi. ${ }^{4,9}$ Regional anestesi seperti blok perifer dan neuroaxial blok dapat menguntungkan dalam hal pencegahan aspirasi, kegagalan intubasi, dan manajemen nyeri pasca operasi yang lebih baik. Pertimbangan utamanya adalah pengunaan yang cermat untuk mencegah hipotensi maternal sehingga sirkulasi uteroplasental dapat terjaga..$^{13,14}$ Pemilihan tehnik epidural dikarenakan kejadian 
dan beratnya kejadian hipotensi lebih rendah sehingga dapat menjaga tekanan darah uterina, tidak ada tusukan di duramater sehingga tidak mempengaruhi tekanan intrakranial, selain itu dapat digunakan untuk analgesia post operasi. Pemilihan untuk tehnik anestesi dengan pertimbangan resiko neurologi pada SOL (Gambar 2). ${ }^{11}$

Pada pasien ini saat preoperatif tidak didapati keluhan, pemeriksaan fisik dalam batas normal, tidak ada tanda-tanda TIK meningkat, kecuali hasil laboratorium lekositosis. Hasil diskusi dengan tim Anestesi, maka dilakukan tehnik regional anestesi epidural sitting position proyeksi median puncture di L3L4 dengan ujung kateter tip di L1, obat levobupivacain 0,5\% $11 \mathrm{ml}$. Target blok di Th VI-S2. Pada wanita hamil dengan tumor otak yang akan dilakukan SC, selama tidak ada kontraindikasi untuk neuroaxial anestesi, dapat dilakukan. Tehnik ini pun dilakukan untuk tetap menjaga hemodinamik tetap stabil, mencegah peningkatan tekanan intrakranial, bila dilakukan dengan general anestesi. Pada general anestesi dipertimbangkan tekanan intrakranial dan efek lambung penuh.

Pertimbangan untuk tidak dilakukan dilakukan general anestesi adalah menghindari potensi valsava berhubungan dengan intubasi, meminimalkan ekspose obat-obatan general anestesi dengan janin, melibatkan ibu yang dalam kondisi sadar untuk partisipasi dalam kelahiran (sisi psikologis). Pertimbangan lain yaitu teratogenisitas obat anestesi, pencegahan asfiksia janin, pencegahan keguguran dan persalinan prematur, menghindari peningkatan tekanan intra-serebral, jalan napas sulit dan risiko aspirasi yang lebih tinggi. Pengaruh hipoksia pada ibu akan menyebabkan perubahan asam basa pada neonatus dan depresi biokimia. Oksigen fetus dipengaruhi oleh konsentrasi oksigen inspirasi pada ibu. Semakin tinggi oksigen konsetrasi oksigen yang diinspirasi ibu akan meninggikan tekanan oksigen pada ibu dan fetus. ${ }^{4}$ Pada sirkulasi uteroplasental tidak terdapat mekanisme autoregulasi sehingga penurunan signifikan tekanan darah ibu dapat menganggu aliran uteroplasental dan menyebabkan iskemia janin.
Oleh karena itu selama periode intraoperatif dijaga agar tidak terjadi hipotensi berkepanjangan. Resusitasi cairan dapat menjadi pilihan utama sebelum vasopresor atau inotropik, kecuali pada pasien dengan komorbid ginjal maupun jantung berat. Efedrin dan fenilefrin merupakan obat vasoaktif yang terbukti aman diberikan selama kehamilan untuk menangani hipotensi maternal. ${ }^{13}$

\section{Simpulan}

Selama tidak didapati kontra indikasi untuk neuroaxial anestesi, wanita hamil dengan SOL yang tidak mempunyai efek massa, hidrosefalus, atau klinis kearah peningkatan TIK, dapat dilakukan tindakan dengan neuroaxial anestesi. Wanita hamil dengan resiko tinggi terjadinya herniasi dari puncture di dura, bila didapatkan lesi yang menekan jaringan otak normal, dan menyebabkan pergeseran garis tengah ke samping atau bawah, dengan atau tanpa obstruksi aliran CSF. Pemahaman resiko wanita hamil terjadi kelainan neurologi akibat SOL tidak hanya dipersiapkan pada pasien dengan resiko rendah saja pada neuroaxial anestesi, melainkan juga untuk mengontrol TIK pada general anestesi.

\section{Daftar Pustaka}

1. Intisar AM, Fahad AM. Advanced case of glioblastoma multiforme and pregnancy: An ethical dilemma.Neuroscience.2015;20 (4):388-91.

2. Bisri $\mathrm{T}$, Wahjoeningsih $\mathrm{S}$, Suwondo BS. Seksio sesarea pada pasien tumor otak. Anestesi Obstetri. Bandung : Saga Olahcitra. 2013:201-4.

3. Smith IF, Skelton V. An unusual intracranial tumour presenting in pregnancy. Int $\mathrm{J}$ Obstetric Anesth 2007; 16:82-5.

4. Leffert LR, Schwamm LH. Neuroaxial anesthesia in parturients with intracranial pathology. neuroaxial anesthesia and intracranial lesion in pregnancy. http://anesthesiology.pubs.asahq.org. 
2013;119:703-18.

5. Bisri T. Neurofisiologi. Penanganan Neuroanestesia dan Critical Care Cedera Otak Traumati. Edisi 3. Bandung: Fakultas Kedokteran Universitas Padjajaran. 2012;118.

6. Saleh SS. Neurofisiologi. Sinopsis Neuroanestesia Klinik. Fakultas Kedokteran Universitas Airlangga. 2012;1-18.

7. Chestnut DH, Wong CA, Tsen LC, Ngan Kee WD, Beilin Y, Mhyre JM. Neurologic and Neuromuscular. Chestnut's Obstetric Anesthesia Principles and Practice. 5th Edition. Elsevier. 2014;1129-32.

8. Price SA, Wilson LM. Tumor Susunan Saraf Pusat. Patofisiologi Konsep Klinis prosesproses Penyakit. Edisi 4. EGC. 1995:103040.

9. Finfer SR. Management of labour and delivery in patient with intracranial neoplasms. Br J
Anesth. 1991;67:784-9.

10. Datta S. Neurologic and Muscular Disease. Anesthetic and Obstetric management of High Risk Pregnancy. 3rd Edition. Springer. 2004;138-39.

11. Klein JP, Hsu L. Neuroimaging during pregnancy. Semin Neurol. 2011; 31:361-73

12. Girault A, Dommerguest M, Nizard J. Impact of maternal brain tumors on perinatal and maternal management and outcome: a single referral center retrospective study. EJOGRB. 2014; 183:132-6.

13. Upadya M, Saneesh PJ. Anaesthesia for nonobstetric surgery during pregnancy. Indian J Anaesth. 2016 Apr:60(4):234-41.

14. Velde MV. Chapter 16: Nonobstetric surgery during pregnancy. In Chestnut D et all, Chestnut's Obstetric anesthesia: principles and practice (fifth ed). Philadelpia: Elsevier.2014;358-76. 